\title{
A cultura democrática na gestão da escola pública: um estudo da análise do discurso dos conselheiros escolares
}

\author{
Luciana Rosa Marques \\ Universidade Federal de Pernambuco, Brasil
}

\begin{abstract}
Resumo
Este trabalho discute a formação de uma cultura democrática escolar a partir da análise do discurso dos membros do Conselho Escolar de três escolas públicas pernambucanas. Adota o conceito de cultura proposto por Hall (1997), que se articula ao conceito de discurso. Utiliza os referenciais das novas teorias do discurso, de corte 'laclauniano', para análise dos dados empíricos. Considera, ainda, que a gestão democrática não é instituída por leis ou normatizações, mas tem um caráter instituinte, podendo ser construída de diferentes formas em cada escola. Trata o discurso como prática social, que tanto pode manter como transformar as relações sociais. A análise dos dados empíricos revelou que as práticas discursivas constroem significados à gestão de cada escola, que são constitutivas de sua cultura. Verificou-se, ainda, que a gestão escolar vem se estruturando a partir de práticas democráticas que podem contribuir, também, no processo de democratização da sociedade.
\end{abstract}

Palavras-chave

Gestão Escolar; Democracia; Cultura; Conselho Escolar

\section{Introdução}

A partir da década de setenta do século $\mathrm{XX}$, o regime de acumulação fordista começa a viver uma crise fiscal e política, ao mesmo tempo em que 
são inauguradas transformações na base da economia capitalista em todo o mundo, particularmente o ocidental. Até então, tinha-se um modelo produtivo calcado na rígida hierarquia e especialização das tarefas, segundo o qual a produtividade do trabalho podia ser aumentada por meio da decomposição e fragmentação dos processos de trabalho, a partir de conjunto rigoroso de práticas de controle do trabalho, assim como de tecnologia e hábitos de consumo. A esse modelo produtivo corresponderia um determinado tipo de trabalhador, um tipo de homem.

São características, ainda, deste modelo produtivo a produção e consumo de massa e um modo de regulação que implica mecanismos que tratam de ajustar o comportamento contraditório e conflitante dos indivíduos.

A partir de 1973, quando se torna mais evidente a incapacidade desse modelo conter as contradições inerentes ao capitalismo, começam a emergir nos países centrais novas formas de organização da produção, fundadas na flexibilização: "A acumulação flexível se apoia na flexibilidade dos processos de trabalho, dos mercados de trabalho, dos produtos e padrões de consumo" (Harvey, 1996, p. 140). O modelo pós-fordista baseia-se no princípio da flexibilidade, como resultado da competição intensificada para reduzir os mercados; um processo de trabalho centrado num trabalho contingente, negociado e essencializado, baseado no trabalho em equipe, na autogestão e em múltiplas, mas básicas, habilidades, além de modos de regulação governados pela ideologia do livre mercado, individualismo e caridade privada.

Assim, a especificidade de cada unidade produtiva passa a ser considerada a era da cultura organizacional.

Passa-se de um modelo hierárquico claramente rígido e monocrático, para uma estrutura onde a concentração (elevada) de poder se dá em alguns poucos pólos, quando o núcleo central da organização passa a exercer o controle pela definição dos canais de comunicação e informação e pela distribuição de recursos. Criam-se, assim, pequenas unidades descentralizadas, gozando de aparente autonomia. Para Gómez (2001, p. 87), há a imposição de uma nova forma de organização cooperativa, caracterizada pela polivalência e flexibilidade das estruturas.

As transformações ocorridas na base produtiva trazem consigo a "necessidade" de reformulação do aparato estatal. No modelo fordista, era 
necessário um Estado forte e controlador da economia, que fizesse investimentos em infra-estrutura, necessários ao crescimento da produção e do consumo, através do qual se pretendeu regular o mercado, para manter o pleno emprego e uma economia orientada para a demanda. A administração estatal devia, ainda, sustentar a provisão pública das políticas sociais, oferecendo um "nível mínimo de vida", como elemento constitutivo da responsabilidade coletiva de todos os cidadãos e cidadãs.

No modelo neoliberal, por sua vez, o Estado deve ser mínimo, deixando-se à mão invisível do mercado a regulação econômica: "menos Estado e mais mercado" é a máxima neoliberal. Porém, a intervenção estatal torna-se necessária para compensar as falhas do mercado, tais como danos ao meio ambiente e combate ao monopólio, entre outras. Com relação às políticas sociais, inclusive as educativas, o Estado deve, paulatinamente, delegar ao setor privado e/ou público não estatal a responsabilidade por elas.

Esse movimento de limitação da atuação estatal acarreta o risco da perda do espaço público como direito ${ }^{1}$. Dessa forma,

podemos estar assistindo à transformação de direitos e obrigações com e dos cidadãos, em razão de seu status como cidadão, na aceitação de direitos e obrigações em razão de seu acesso ao mercado, ou seja, à compra e venda de serviços por quem pode (o cliente com recursos) comprá-los de quem o vende [...] a conseqüência mais preocupante da deterioração, e inclusive, da dissolução dos espaços e das instituições públicas, é o desamparo e a desmobilização que provocam, precisamente, nos menos favorecidos (Gómez, 2001, p. 96).

Essas mudanças encontram reflexos na forma proposta de gestão da educação. Com a adoção dos pressupostos neoliberais pelo poder central, a partir de 1995 começam a ser implantadas diretrizes no sentido de democratizar os sistemas escolares e a gestão das escolas. Dessa forma, assistimos a uma série de ações que visam tanto democratização da gestão das escolas públicas brasileiras, como dos próprios sistemas escolares, sejam eles estaduais ou municipais.

Cumpre considerar, contudo, que a discussão sobre a democratização da gestão escolar é uma demanda antiga de pesquisadores e trabalhadores da área, defendida por estes como um dos mecanismos importantes para se alcançar uma educação pública de qualidade, universal, como exercício de cidadania. Assim, mesmo sendo implantada com base nos princípios 
neoliberais, a gestão democrática no sistema educacional público abre possibilidades para que se construa uma escola pública de qualidade, que atenda aos interesses da maioria da população brasileira, além de representar uma possibilidade de vivência e aprendizado da democracia, podendo, portanto, tomar um sentido diferenciado do proposto pelos fazedores de política. Nessa perspectiva, e admitindo o movimento dialético da história, podemos considerar que a implantação das novas diretrizes da política educacional não está, em princípio, pré-determinada e pode, por conseguinte, tomar sentidos diferenciados.

Tomando por base esta idéia, o presente trabalho teve por objetivo apreender os significados da democracia na gestão da escola pública. A coleta de dados foi realizada através de observações e entrevistas com membros do Conselho Escolar de 3 (três) escolas da rede municipal do Cabo de Santo Agostinho - região Metropolitana do Recife, Pernambuco. Parte-se do princípio de que as relações democráticas se consolidam a partir das práticas "cotidianas"2, construindo a cultura da escola. Desse modo, pode se constituir de forma diferenciada em cada escola. Buscou-se, assim, verificar como a gestão democrática se materializa nas escolas estudadas.

\section{A cultura escolar}

Consideramos, neste trabalho, que não existe um modelo de democracia de validez universal, sendo necessária a institucionalização de práticas democráticas nas diversas formas de relações sociais, que construiriam, assim, uma sociedade mais inclusiva. Tomando por base a idéia da indecibilidade e da incompletude da democracia, que é uma construção contínua e contingente que se dá através de práticas articulatórias nos diferentes espaços sociais, é pertinente o estudo da cultura escolar, tendo em vista que em cada escola a construção de relações democráticas pode se dar de forma diferenciada.

Em seu estudo sobre a interpretação da cultura, Geertz (1989, p. 36) demonstra a polissemia característica do conceito, assumindo-o a partir de uma perspectiva interpretativa, que busca significados, e não como um estudo experimental, à procura de leis. Tal posição provém de seu entendimento de que o homem é um animal amarrado a teias de significados que ele mesmo teceu, e a cultura seria, portanto, a interpretação dessas teias. 
O autor tece críticas, ainda, àqueles que defendem a existência de um caráter universal da cultura humana. Para ele, a produção cultural precisa ser situada nas relações sociais em que adquire significação, pois

o objetivo é tirar grandes conclusões a partir de fatos pequenos, mas densamente entrelaçados; apoiar amplas afirmativas sobre o papel da cultura na construção da vida coletiva empenhado-as exatamente em especificações complexas (Geertz, 1989, p. 38).

Dessa forma, o estudo da cultura é sempre incompleto, na medida em que ela está em constante movimento, sendo criada e recriada, não podendo ser descritivo, mas interpretativo. Assim, considera a cultura como o tecido de significações em função dos quais os homens interpretam suas experiências e guiam suas ações. A cultura poderia ser pensada como a articulação entre o que é instituído e o que é instituinte, caracterizando-se por um processo contínuo e ativo de construção da realidade, um fenômeno ativo, vivo, em que as pessoas criam e recriam seus mundos (Teixeira, 2002, p. 19).

Para McLaren (1991, p. 29), a cultura (da escola) é informada por determinantes específicos de classe social, ideologia e estruturas da sociedade, perspectiva que ampliaria a interpretação de Geertz. A cultura se expressa através de rituais inter-relacionados e sistemas de rituais. $\mathrm{O}$ autor considera o ritual como um evento político e como parte das distribuições objetificadas do capital cultural dominante na escola, destacando, ainda, que "nas sociedades modernas as produções culturais superam as produções econômicas como base de valores, estilos de vida e visões de mundo compartilhadas" (Geertz, 1989, p. 30).

No seu entendimento, os estudos sobre educação não têm conseguido explorar a maneira pela qual a cultura, como ação ritual, constitui comportamentos, principalmente porque os estudos antropológicos da educação, em sua maioria, têm considerado a escola como local politicamente neutro, sem problematizar sua relação com a sociedade. Assim, "qualquer análise dos rituais escolares deve ser colocada num contexto de cultura que problematize a relação entre escola, poder, conflito e classe" (p. 61). Para ele, os rituais surgem das coisas ordinárias da vida, nutrindo-se da experiência vivida, expressando-se como a "liturgia do cotidiano". Portanto, a explicação de um ritual é, inevitavelmente, o exame das dimensões simbólicas da vida social. 
Assim como Geertz, Gómez (2001) também parte das diferentes interpretações do conceito de cultura para construir a sua definição. Para ele, a cultura é

o conjunto de significados, expectativas e comportamentos compartilhados por um determinado grupo social, o qual facilita e ordena, limita e potencia os intercâmbios sociais, as produções simbólicas e materiais e as realizações individuais e coletivas dentro de um marco espacial e temporal determinado. A cultura, portanto, é o resultado da construção social, contingente às condições materiais, sociais e espirituais que dominam um espaço e um tempo. Expressase em significados, valores, sentimentos, costumes, rituais, instituições e objetos, sentimentos (materiais e simbólicos) que circundam a vida individual e coletiva da comunidade (p. 17).

Hall (1997) discute a centralidade do conceito de cultura na atualidade, articulando-o ao conceito de discurso. Epistemologicamente, a centralidade da cultura estaria nas mudanças paradigmáticas que a virada cultural provocou no interior das disciplinas tradicionais, no peso explicativo que 0 conceito carrega e no seu papel constitutivo, e não dependente da análise social, o que a colocaria em um espectro mais abrangente de instituições e práticas. Para ele "a cultura não é nada mais do que a soma de diferentes sistemas de classificação e diferentes formações discursivas as quais a língua recorre a fim de dar significação às coisas" (p. 29). O autor demonstra, ainda, que a cultura tem papel central na construção da subjetividade, da identidade e da pessoa como ator social. Desta forma, práticas culturais e práticas discursivas seriam correlatas ${ }^{3}$, pois "toda prática social tem condições culturais ou discursivas de existência. As práticas sociais, na medida em que dependem dos significados para funcionarem e produzirem efeitos se situam dentro do discurso, são discursivas" (p. 33).

Ao inserir a discussão da cultura no espaço escolar, ou seja, em uma instituição social, Fourquin (1993, p. 147) nos mostra que os conteúdos que "a escola transmite não são, com efeito, somente saberes no sentido estrito. São também conteúdos mítico-simbólicos, valores estéticos, atitudes morais e sociais, referenciais de civilização".

Consideramos, assim, que a escola não é um espaço de simples aquisição de conhecimentos, mas de aprendizados outros, como o das práticas democráticas. Os intercâmbios que se realizam no "cotidiano" escolar trazem efeitos no pensamento, sentimentos e condutas da comunidade 
escolar, ou seja, constroem identidades 4 . Dessa forma, entendemos que as diretrizes das políticas de democratização se concretizarão na escola, locus de materialidade das políticas educacionais, e que serão implantadas a partir da rede de significações produzidas no "cotidiano" de cada escola, podendo (ou não) ser criada uma cultura democrática nas Unidades Escolares.

Entendemos, ainda, com base em Hall (1997, p. 40), que

cada instituição ou atividade social gera e requer seu próprio universo distinto de significados e práticas - sua própria cultura. Assim sendo, cada vez mais, o termo está sendo aplicado às práticas e instituições que manifestamente não são parte da "esfera cultural", no sentido tradicional da palavra. De acordo com este enfoque todas as práticas sociais, na medida em que sejam relevantes para o significado ou requeiram significado para funcionarem, têm uma dimensão cultural.

A escola é uma organização da sociedade e sua cultura constitui-se em um prolongamento da cultura social. No entanto, isto não significa que as organizações escolares possam ser consideradas de modo uniforme, pois comportam diferentes sistemas de valores que criam realidades organizacionais diferenciadas. "A existência de padrões culturais nas organizações pode ser vista como fator de diferenciação das mesmas a partir da ação e da interação de seus membros" (Teixeira, 2002, p. 22). Assim, a cultura organizacional pode ser considerada a forma como as coisas acontecem no âmbito de uma instituição, dirigindo a atenção para o significado simbólico dos aspectos racionais da vida organizacional, o que permite o entendimento de significados subjetivos das estruturas e práticas, fundamentais ao entendimento do funcionamento "cotidiano" da organização. Nesse sentido, a organização pode ser considerada como uma realidade construída.

Assim, estudar a gestão das Unidades Escolares a partir da análise de discurso requer situá-la na dimensão do estudo da cultura escolar ${ }^{5}$, pois é através da reapropriação, re-significação e reinterpretação que as diretrizes da política educacional para a gestão das escolas serão relativizadas e adaptadas à realidade de cada Unidade Escolar, já que, como mostra Teixeira (2002, p. 40), com base no pensamento de Cândido,

se há uma organização administrativa igual para todas as escolas de determinado tipo, pode-se dizer que cada uma delas é diferente da outra, por apresentar características derivadas de sua sociabilidade própria. 
Nesse sentido, os Conselhos Escolares, unidades gestoras da escola, de caráter deliberativo, são entendidos como um espaço político de construção social contingente, negociação de conflitos, confrontos e interesses, através de práticas discursivas, onde são construídos significados simbólicos, capazes de gerar mudanças no comportamento da comunidade escolar ${ }^{6}$, em relação à gestão da escola e, portanto, na cultura escolar.

O Conselho é considerado uma estrutura discursiva, que constitui e organiza relações que se dão no interior da escola, através de práticas articulatórias que constroem sentido à gestão escolar. No entanto, os sentidos da gestão construídos através das práticas discursivas pelos Conselheiros Escolares têm a marca própria de cada escola, tendo em vista que ela representa uma organização, sendo, portanto, culturalmente diferente.

Nesse sentido, as práticas discursivas constroem significados à gestão de cada escola que são constitutivos de sua cultura, pois mudanças nas organizações passam por uma mudança cultural e a gestão escolar democrática no Brasil seria uma prática inovadora, tendo em vista o caráter autoritário historicamente predominante na gestão das escolas públicas.

\section{A teoria do discurso como forma de apreensão da realidade}

O crescimento do interesse pela análise do discurso é ao mesmo tempo conseqüência e manifestação da "virada lingüística", precipitada por críticas ao positivismo, pelo prodigioso impacto de idéias estruturalistas e pósestruturalistas e pelos ataques pós-modernistas à epistemologia. Sua origem como crítica à ciência social tradicional significa que ela possui uma base epistemológica diferenciada das outras metodologias, o que é denominado construcionismo social, construtivismo ou construcionismo. Mesmo existindo diferentes abordagens de análise do discurso, todas partilham da rejeição da noção realista de que a linguagem é um meio neutro de refletir ou descrever o mundo e da convicção na importância central do discurso, que é uma forma de ação no mundo, na realidade social que ele constrói.

Embora com muitas proximidades, tanto conceituais como metodológicas, Teoria do Discurso (TD) e Análise do Discurso (AD) não são exatamente uma mesma estratégia intelectual. 


\begin{abstract}
A TD trabalha a dimensão da linguagem na análise de objetos empíricos pela sua inscrição numa problemática clara de implicação política e ontológica[...] enquanto a $A D$ - embora não seja um ramo da lingüística - pode ser inteiramente realizada no âmbito desta [...] sem maiores pretensões de fazer intervir hipóteses sobre como se constituem e transformam o social ou os atores sociais, ou de explicar o social a partir do discurso. A despeito de haver muitas definições de discurso na $A D$, é importante admitir uma importante diferença entre estas e a TD [...] trata-se da rejeição que a TD faz da distinção entre discursivo e extra-discursivo e de sua definição formal de discurso que transcende o domínio da linguagem tal como trabalhada na lingüística e pressuposta como um dado empírico pelo mainstream das ciências sociais (Burity, 2007, pp. 74-75, grifo nosso).
\end{abstract}

Neste trabalho, o discurso é tomado como uma prática social, ou seja, como forma de construção social, cuja condição ontológica é a política, o que implica em considerá-lo como uma forma de ação das pessoas sobre o mundo e sobre os outros, expressando as relações sociais que se colocam na sociedade. Constitui-se, portanto, em ações, seleções, escolhas, linguagens, enfim, todas as produções sociais das quais é expressão, podendo ser um caminho para o entendimento dos sentidos produzidos no "cotidiano". "O discurso, como um sistema de relações (entre significante e significado, entre linguagem e ação, entre elementos de diferentes outros discursos, etc.) encerra uma articulação orgânica entre língua e ato, entre o lingüístico e o extra lingüístico" (Burity, 2007, p. 75).

O foco de nosso trabalho são as práticas discursivas que correspondem a momentos ativos no uso da linguagem, momentos de resignificação, de rupturas, de produção de sentidos e, portanto, de linguagem em ação, ou seja, como as pessoas produzem sentidos e se posicionam em relações sociais "cotidianas". Segundo Fairclough (2001, p. 66), em sua análise da obra de Foucault,

o que é de maior significação aqui para a análise do discurso é a visão do discurso como constitutiva - contribuindo para a produção, transformação e a reprodução dos objetos da vida social. Isso implica que o discurso tem uma relação ativa com a realidade, que a linguagem significa a realidade no sentido de construção de significados para ela.

A análise de uma prática discursiva focaliza os processos de produção, consumo e mudança textual, o que exige referência aos ambientes econômicos, políticos e institucionais particulares nos quais o discurso é gerado. Porquanto, 
[...] não há como dissociar o processo de apreensão do real de processos de significação, os quais, por sua vez, implicam tanto em redes argumentativas quanto nas práticas concretas e nas instituições através das quais tais representações podem tornar-se significativas, compartilhadas ou impostas (conforme o façam por via democrática ou autocrática). Enfim, significa admitir uma acepção do termo que indica sua dinamicidade, o jogo das diferenças num sistema que altera os limites de sua própria configuração: discurso (Burity, 1994, p. 149, grifo do autor).

Desta forma, todas as configurações sociais são significativas e os significados das palavras e práticas dependem do espaço discursivo, que é construído por práticas articulatórias em que se colocam. Segundo Fairclough (2001, p. 91),

o discurso contribui para a constituição de todas as dimensões da estrutura social que, direta ou indiretamente, o moldam e restringem: suas próprias normas e convenções como também relações, identidades e instituições que Ihe são subjacentes. O discurso é uma prática, não apenas de representação do mundo, mas de significação do mundo, constituindo e construindo o mundo em significação.

$O$ autor identifica três funções da linguagem e dimensões de sentido que coexistem em todos os discursos. A primeira é a função identitária, que se relaciona aos modos pelos quais as identidades sociais se estabelecem no discurso. A segunda função, a relacional, diz respeito à maneira como as relações sociais entre os participantes de processos discursivos são representadas e negociadas. E, por fim, a função ideacional é referente aos modos pelos quais os textos significam o mundo e seus processos, entidades e relações.

Enquanto prática social, o discurso é tomado como prática política, que transforma, mantém e estabelece as relações de poder e as entidades coletivas em que tais relações se colocam, havendo, portanto, uma competição para fixar sentidos ${ }^{7}$ a configurações significativas particulares. Segundo Laclau e Mouffe (1989, p. 113),

discursos são estruturas descentradas onde os sentidos são constantemente negociados e construídos. Esta estrutura descentrada, ou 'totalidade' estruturada, ou ainda, discurso, é o resultado de práticas articulatórias estabelecendo relações entre elementos com diferenças não articuladas discursivamente. 
Esta perspectiva de discurso abre a possibilidade para reativação da origem política contingente do que é fixado e objetivamente apresentado, abrindo espaço para novos antagonismos e fixação de novos conteúdos e formas que não se colocavam até então, tornando possível, assim, a articulação de uma multiplicidade de discursos concorrentes e, conseqüentemente, da transformação dos agentes e práticas sociais. Assim, a prática de articulação, como deslocamento/fixação de um sistema de diferenças penetra a densidade inteiramente material da multiplicidade de instituições, rituais e práticas através das quais uma estrutura discursiva é estruturada (Laclau \& Mouffe, 1985). Dessa forma, a prática discursiva tanto pode contribuir para a reprodução da sociedade, como para sua transformação.

\begin{abstract}
À medida que os produtores e os intérpretes combinam convenções discursivas, códigos e elementos de maneira nova em eventos discursivos inovadores estão, sem dúvida, produzindo cumulativamente mudanças estruturais nas ordens de discurso: estão desarticulando ordens de discurso existentes e rearticulando novas ordens de discurso, novas hegemonias discursivas. Tais mudanças estruturais podem afetar apenas a ordem de discurso 'local' de uma instituição, ou podem transcender as instituições e afetar a ordem de discurso societária. $O$ foco de atenção na investigação da mudança discursiva deveria manter a alternância entre o evento discursivo e tais mudanças estruturais, porque não é possível avaliar a importância do primeiro para os processos mais amplos de mudança social sem considerar as últimas, da mesma forma que não é possível avaliar a contribuição do discurso para a mudança social sem considerar o primeiro (Fairclough, 2001, p. 128).
\end{abstract}

Nesta perspectiva, os Conselhos Escolares são tomados enquanto estruturas discursivas, ou seja, práticas articulatórias que organizam e constituem as relações sociais. Não podem ser considerados, portanto, simplesmente como a expressão de algo já adquirido, mas como construtores de novos significados que podem ou não fixar-se, sentidos que se colocam como referências a partir da disputa por significados construídos nas relações sociais que se constroem na escola, contribuindo, assim, para a consolidação (ou não) de mudanças no discurso.

Os Conselhos Escolares organizariam as relações sociais referentes à gestão da escola, que vão construir práticas articulatórias que darão sentido à gestão escolar. Desta forma, poderão ou não ser instituídas práticas democráticas na gestão da Unidade Escolar, dependendo dos sentidos fixados, e o Conselho poderá ou não ser uma instância de transformação das relações sociais que se estabelecem no espaço escolar. 


\section{A construção de uma cultura democrática na escola}

Buscamos apreender, através de entrevistas com catorze (14) Conselheiros Escolares e com três (3) diretores, além da observação de três (3) reuniões dos Conselhos Escolares, os discursos e as práticas democráticas na gestão das escolas, que indicariam mudanças na gestão escolar e sua possível contribuição na democratização da própria sociedade.

Os Conselhos Escolares de todas as escolas estudadas são formados por representantes dos diferentes segmentos que compõem a comunidade escolar. No entanto, em alguns deles, estes representantes não foram eleitos, mas sim indicados, tendo havido, inclusive, em uma das escolas, uma préseleção dos alunos que seriam apontados para concorrer à eleição, em função de seu comportamento, utilizando-se, portanto, de uma postura classificatória e excludente, fundamentalmente, antidemocrática, para subsidiar a participação dos alunos no Conselho. Este episódio nos mostra como a democracia pode ser impregnada de contradições.

É consenso, entre os Conselheiros, que a importância do Conselho está na divisão de responsabilidades, tornando as relações da escola mais horizontais, deixando de haver uma concentração de poder na mão do dirigente. Parece, assim, estar sedimentada a concepção do Conselho como instrumento e, mais ainda, como condição de democratização da gestão, que é de responsabilidade coletiva e não centrada na figura do diretor.

Percebemos ainda o destaque dado pelos Conselheiros, quando indagados sobre a importância do Conselho Escolar, à maior integração entre pais e escola. Assim, através do Conselho, a escola também cumpre uma de suas incumbências determinadas pela $\mathrm{LDB}^{9}$, no artigo 12 , item $\mathrm{VI}$, que é a de "articular-se com as famílias e a comunidade, criando processos de integração da sociedade com a escola". Via democratização, a escola assumiria o seu caráter público, no sentido da oferta de uma educação de qualidade que atenda aos interesses da maioria da população brasileira.

Observamos muitas diferenças nos temas ${ }^{10}$ tratados nas reuniões dos Conselhos Escolares, o que reforçou nossa hipótese de que a democracia se constrói de forma diferenciada em cada escola, a partir da ação das pessoas, constituindo a sua cultura. Enquanto em uma das escolas se discute apenas questões financeiras nas reuniões do Conselho, na outra se discute as financeiras e as administrativas e na terceira são discutidas as questões 
pedagógicas, financeiras e administrativas. Percebemos que os assuntos tratados diferem de uma escola para a outra, representando, portanto, avanços maiores ou menores na democratização da gestão escolar.

No mesmo sentido, a própria dinâmica das reuniões nos indica diferenças no processo participativo em cada umas das escolas. Em uma delas, as pessoas parecem estar "mais à vontade" nas reuniões do Conselho Escolar, na outra percebemos uma centralização na figura da presidente do Conselho (uma professora) e na do diretor da escola, enquanto que na terceira escola as reuniões não são sistemáticas ${ }^{11}$.

Verificamos, ainda, que em todas as escolas a participação dos diferentes segmentos no Conselho Escolar se dá "de forma igualitária"12 e que as diferenças existentes são provenientes de características pessoais e não do segmento que a pessoa representa. Todos os conselheiros entrevistados consideraram que as opiniões de todas as pessoas eram respeitadas da mesma forma, com o mesmo peso, sem haver a prevalência de opinião em função do segmento representado, assim como há o respeito do dirigente pelas decisões do Conselho, que são colocadas em prática pelo mesmo, o que indica que a participação envolve a distribuição de poder e não apenas a colaboração.

Um estudo sobre democracia não poderia desconsiderar a questão da autonomia, na medida em que estes dois conceitos têm uma extrema interrelação. Assim, "só a autonomia garante o poder, os recursos e a capacidade de decisão colectiva necessários ao funcionamento democrático de uma organização" (Barroso, 2004, p. 74).

A matriz discursiva em que se apoia a maior parte das entrevistas é a que aborda a autonomia em sua dimensão administrativa, com especial ênfase à determinação da aplicação de recursos financeiros recebidos pela escola, que, no entanto, muitas vezes, já vem com sua utilização prédeterminada (custeio, capital, material permanente, material de consumo), o que restringe a liberdade da escola e leva-a, por exemplo, a realizar campanhas de arrecadação de verbas para compra de equipamentos ou materiais dos quais realmente necessite. Ainda, para os conselheiros, a autonomia não pode ir de encontro ao cumprimento da legislação, envolvendo, portanto, liberdade, mas não independência. Dessa forma, podese fazer "tudo" dento do limite que é imposto pela legislação. 
Por fim, buscamos identificar as mudanças geradas na gestão da escola após a implantação do Conselho Escolar. Os discursos dos conselheiros sugerem que houve muitas mudanças após a implantação dos Conselhos Escolares como órgãos gestores da escola, assim como houve também conflitos em seu processo de construção, embora se perceba que, na maioria dos discursos, os aspectos enfatizados são diferentes.

O primeiro sentido da mudança destacado refere-se à horizontalização das decisões na escola, que deixam de ser concentradas na pessoa do diretor e passam a ser de responsabilidade coletiva, inclusive havendo a participação na definição da utilização dos recursos financeiros e divulgação para todos sobre a aplicação dos mesmos. Assim, tanto os acertos quanto os erros passam a ser de responsabilidade coletiva, sendo compartilhados por toda a comunidade escolar. Este é o sentido que parece estar mais fixado nos discursos sobre as mudanças geradas pelo processo democrático da gestão da escola, via Conselho Escolar. Percebemos, nestes discursos, o destaque da mudança das relações de poder na escola.

Além disto, no discurso dos Conselheiros sobre as mudanças na gestão da escola, é destacado também o compromisso coletivo com a escola, que é possibilitado pela participação. Assim, a participação passa também pelo comprometimento das pessoas com projetos coletivos, em que cada um tem suas responsabilidades que, se não forem cumpridas, comprometem o trabalho como um todo. Além disto, a prática participativa proporciona uma maior integração dos pais e da própria comunidade na escola.

No discurso dos Conselheiros aparece, ainda, a melhoria do ensino como uma mudança proveniente da ação do Conselho, possibilitada pela maior aproximação dos pais com a escola e com a própria direção e corpo docente. Esta aproximação fez com que as reivindicações dos pais fossem atendidas, uma vez que, anteriormente, estes não eram sequer recebidos pela direção ou pela Secretaria de Educação. Assim, a democratização possibilitou que a escola passasse a estar ao serviço da comunidade que atende, respondendo a seus interesses e demandas, concorrendo para que ela cumpra efetivamente o seu caráter público.

Da mesma forma, contribuindo com a melhoria da qualidade do ensino aparece a recuperação/ampliação/reformas da estrutura física da escola, que, inclusive, possibilitou a ampliação da oferta de ensino em uma das escolas. 
No entanto, reforçando a idéia de que as políticas educacionais democráticas são essenciais para que a democracia possa ser construída nas Unidades Escolares, nesta escola, especificamente, após muita luta e conflito para a consecução da implantação de turmas de quinta a oitava série, houve o fechamento destas mesmas turmas, quando ocorreu a mudança de governo, o que provocou um arrefecimento do próprio Conselho Escolar, que se percebeu impotente. A dirigente, que havia sido eleita, encampou e defendeu as novas determinações da Secretaria de Educação, visando à sua permanência no cargo. Este episódio pode demonstrar quão difícil é o processo de construção democrática e, principalmente, a sua solidificação, que só poderá se dar com a confluência de vários fatores.

\section{Considerações finais}

Nossa pesquisa demonstrou que nas escolas estudadas a democracia vem se solidificando como uma prática política, baseada em relações horizontais, contribuindo, portanto, para a formação política dos sujeitos sociais pertencentes ao espaço escolar. As entrevistas e observações realizadas nas escolas nos demonstraram que efetivamente a gestão vem se construindo de forma democrática, com a participação dos representantes dos diferentes segmentos da comunidade escolar, que são tratados de forma igualitária, com respeito a suas diferenças, que têm direito à voz, e que são, portanto, reconhecidos. Também percebemos que, independentemente do segmento que representam, os conselheiros têm suas argumentações respeitadas de igual forma.

Percebemos marcantes diferenças e várias semelhanças entre o que acontece nas escolas que estudamos e o que se verificou em outros espaços escolares (Lima, 2002; Werle, 2003; Santos, 2004; Souza, 2005). Tal achado reforçou nossa suposição de que a democracia se constrói como uma prática articulatória, ganhando diferentes sentidos nos diversos espaços sociais. Desta forma, ela é uma construção das pessoas que formam a escola e não da escola como instituição em si.

Assim, nossa hipótese de que a construção de relações democráticas na escola se daria a partir da cultura de cada escola se confirmou, demonstrando a existência de um campo político nas mesmas. 
No entanto, não podemos entender a cultura escolar como algo perene, na medida em que ela é construída pelas pessoas que fazem a escola, ou seja, pela comunidade escolar, e esta se modifica através do tempo, tanto em função do término do período escolar do corpo discente, quanto por questões burocráticas como transferências e aposentadorias dos profissionais da educação. Além disto, com as eleições diretas, os dirigentes passam a exercer mandatos de dois (2) anos, podendo se reeleger uma única vez. Assim, a direção da escola, que por seu papel de liderança tem decisiva importância na construção da cultura da organização escolar, dispõe de um tempo determinado de exercício do mandato e, portanto, a mudança de dirigente pode se constituir em um fator indutor de mudança na cultura da escola.

A cultura tem papel central na construção da identidade dos atores sociais, que, por sua vez, constroem a cultura, que é contingente e contextual. Nosso estudo empírico confirmou os construtos de Hall que se baseiam na idéia de que cada instituição social gera seu próprio universo de significados e práticas, ou seja, sua própria cultura. Verificamos que, em cada uma das três (3) escolas estudadas, a democracia está sendo construída de forma diferenciada, apesar de todas elas estarem submetidas à mesma política educacional, de fazerem parte da mesma formação discursiva. Cumpre ressaltar, ainda, que verificamos práticas democráticas em todas as escolas, embora estas se construam de forma diferenciada, alcançando também diferentes avanços. Assim, percebemos que as estruturas discursivas tanto são reproduzidas como transformadas na prática social.

É importante destacar também que a democracia, além de não ter um processo homogêneo de construção, pode apresentar distorções. Esta afirmação se verifica a partir de situações em que o Conselho Escolar foi "democraticamente utilizado" para justificar práticas antidemocráticas na escola, como a decisão pela expulsão de uma criança de sete (7) anos cuja mãe havia agredido uma professora, por seu filho ter dito que a mesma havia batido nele ${ }^{13}$. Assim, é possível se instrumentalizar espaços de participação no intuito da adoção de atitudes não democráticas, ou seja, excludentes e classificatórias. Este é um "perigo" que expressa o conflito inerente às relações democráticas, que não eliminam o poder, mas vivenciam-no pelo "pluralismo agonístico"14. 
Consideramos que os conteúdos democráticos dos discursos verificados nas escolas estudadas contribuem com o processo organizativo dos atores escolares, estimulando, assim, a organização social. Na escola, além de conteúdos, aprendemos valores e práticas. Portanto, a institucionalização de práticas democráticas na gestão escolar forma sujeitos democráticos. Supomos que estes sujeitos não serão democráticos apenas na escola, mas em todos os espaços sociais aos quais pertençam, podendo, desse modo, contribuir na democratização dos mesmos e, conseqüentemente, da sociedade. Dessa forma, podemos inferir que as práticas discursivas em mutação, como as observadas neste trabalho, podem ser um elemento importante na mudança social.

\section{Notas}

1 Silva (2003, p. 40) demonstra como as bases ideológicas da política neoliberal foram sendo construídas desde o final da década de 1970, nas quais se observam mudanças na matriz discursiva dos diferentes grupos políticos no que tange à democracia. Dessa forma, para ela, não se deve estranhar que a retirada do Estado da área social tenha sofrido tão pouca resistência por parte dos agentes envolvidos.

2 Cotidiano, neste trabalho, refere-se a dia a dia, e não à teoria do cotidiano desenvolvida por Henri Lefebvre, Agnes Heller e Michel de Certeau, entre outros.

3 Segundo Hall (1997), o clássico exemplo desenvolvido por Marx acerca da diferença entre o trabalho animal e o trabalho humano (o pior dos arquitetos seria mais inteligente do que a melhor das aranhas), hoje poderia ser chamado de concepção discursiva ou cultural da prática social.

4 Segundo Hall, toda a nossa conduta e todas as nossas ações são moldadas, influenciadas, e, dessa forma, reguladas normativamente pelos significados culturais.

5 Segundo Hall (1997, p. 30), dar à cultura um papel constitutivo e determinado na compreensão e na análise de todas as instituições e relações sociais é diferente da forma como a mesma foi teorizada por vários anos nas ciências sociais, em que foi considerada de forma objetiva, dada. Ao contrário, na atualidade, o significado das coisas é entendido não a partir da coisa em si, mas do sistema de classificação em que se inserem. Argumenta ainda que, de fato, não é que 'tudo é cultura', mas que toda prática social depende e tem relação com o significado: consequentemente, que a cultura é uma das condições constitutivas de existência dessa prática, que toda prática social tem uma dimensão cultural. Assim, a materialidade da realidade depende da produção de sentido.

6 Para Hall (1997, p. 39), a cultura nos governa - regula nossas condutas, ações sociais e práticas e, assim, a maneira como agimos no âmbito das instituições e na sociedade mais ampla. 
7 Para Laclau, uma estrutura discursiva não é uma entidade meramente cognitiva ou contemplativa; é uma prática articulatória que constitui e organiza as relações sociais. Uma prática articulatória consiste na construção de pontos nodais fixações parciais que limitam o fluxo entre significado e significante (Mouffe, 1996, p.103) - que fixam parcialmente sentido; o caráter parcial dessa fixação procede da abertura do social, resultante, por sua vez, de um constante transbordamento de todo discurso pela infinitude do campo da discursividade (Laclau \& Mouffe, 1985, p. 113).

8 Sentidos que são fixados de forma contingente, ou seja, são provisórios.

9 Lei de Diretrizes e Bases da Educação Nacional (Lei $n^{\circ}$ 9.394, de 20 de dezembro de 1996).

10 A importância de analisar os temas abordados nas reuniões dos Conselhos Escolares reside em que os assuntos tratados indicarão a distribuição de poder realizada no Conselho. Assim, a análise dos temas discutidos, objeto de decisão coletiva, nos ajudou a entender como se dá a participação no Conselho Escolar.

11 O termo 'sistemáticas' utilizado aqui se refere a reuniões programadas, previamente agendadas e comunicadas aos Conselheiros. Nesta escola, as reuniões acontecem em função da necessidade, ou seja, quando há algo a ser discutido/decidido convoca-se a reunião.

12 De forma igualitária significa que a opinião de todos os participantes é considerada da mesma forma, independente do segmento que o mesmo representa. Assim, ser professor ou diretor não dá maior legitimidade à opinião do Conselheiro.

13 Decisão que foi evitada pela Secretaria de Educação após uma conversa com os Conselheiros e a referida professora.

14 No modelo agonístico de democracia, desenvolvido por Chantall Mouffe, se deve renunciar à naturalização das fronteiras da democracia e dos embates entre seus atores. Dessa forma, os que eram tidos como inimigos, no interior de uma sociedade democrática, devem assumir o papel de adversários que compartilham um conjunto de valores e princípios ético-políticos, cuja interpretação está em disputa. Assim, o pluralismo agonístico enfatiza a importância de reconhecer-se a dimensão conflitual da democracia.

\section{Referências}

Barroso, J. (2004). A autonomia das escolas: uma ficção necessária. Revista Portuguesa de Educação, 17 (2), 49-83.

Brasil (1996). Lei de Diretrizes e Bases da Educação Nacional. Brasília: MEC/INEP.

Burity, J. (1994). Transbordamento do social: qual o jogo da democracia?. In R. Santos, R. Cunha \& L. F. Costa (Orgs.), Contemporaneidade e Política (pp. 137-158). Rio de Janeiro: Sociedade do Livro/Instituto Astrogildo Pereira.

Burity, J. (2007). Teoria do discurso e análise do discurso: sobre política e método. In S. Weber \& T. Leithäuser (Orgs.), Métodos Qualitativos nas Ciências Sociais e na Prática Social (pp. 72-83). Recife: Ed. Universitária da UFPE. 
Fairclough, N. (2001). Discurso e Mudança Social. Brasília: Editora da Universidade de Brasília.

Forquin, J. (1993). Escola e Cultura: As Bases Sociais e Epistemológicas do Conhecimento Escolar. Porto Alegre: Artes Médicas do Sul.

Geertz, C. (1989). A Interpretação das Culturas. Rio de Janeiro: LTC.

Gómez, A. I. P. (2001). A Cultura Escolar na Sociedade Neoliberal. Porto Alegre: ARTMED.

Hall, S. (1997). A centralidade da cultura: notas sobre as revoluções culturais do nosso tempo. Educação e Realidade, 2 (22), 15-46.

Harvey, D. (1996). Condição Pós-Moderna. São Paulo: Loyola.

Laclau, E. \& Mouffe, C. (1985). Hegemony and Socialist Strategy. London: Verso.

Laclau, E. \& Mouffe, C. (1989). Hegemony \& Socialist Strategy: Towards a Radical Democratic Politics. London/New York: Verso.

Lima, L. (2002). Organização Escolar e Democracia Radical: Paulo Freire e a Governação Democrática da Escola Pública. São Paulo: Cortez.

McLaren, P. (1991). Rituais na Escola: em direção a uma Economia Política de Símbolos e Gestos na Educação. Petrópolis: Vozes.

Mouffe, C. (1996). O Regresso do Político. Lisboa: Gradiva.

Santos, T. F. A. M. (2004). Os colegiados escolares no contexto da democratização da gestão. Revista Brasileira de Política e Administração da Educação, 20 (2), 116136.

Silva, I. G. (2003). Democracia e Participação na 'Reforma do Estado'. São Paulo: Cortez.

Souza, N. M. M. (2005). Gestão democrática da educação: entre as políticas oficiais e a prática escolar. Associação Nacional de Pós-Graduação e Pesquisa em Educação. Disponivel em http://www.anped.org.br/27a.htm

Teixeira, L. H. G. (2002). Cultura Organizacional e Projetos de Mudança em Escolas Públicas. Campinas, SP: Autores Associados/São Paulo: UMESP - ANPAE.

Werle, F. O. C. (2003). Conselhos Escolares: Implicações na Gestão da Escola Básica. Rio de Janeiro: DP\&A. 


\section{DEMOCRATIC CULTURE IN PUBLIC SCHOOLS: AN ANALYSIS OF THE SCHOOL COUNCIL MEMBERS DISCOURSE}

\section{Abstract}

This article discusses a democratic culture development in public schools through the analysis of the discourse of School Council members of three public schools in Pernambuco. It adopts the culture concept proposed by Hall (1997), that joins by articulation to the discourse concept, using the reference to Discourse Theory for analysis of the empiric data. It considers that the democratic administration is not instituted by laws, but has an institutionalized character, that could be built in different ways in each school. It treats the discourse as social practice, that can maintain or transforming the social relationships. The empiric data show that the discursive practices build meanings to every school management, which are constituent of its culture. It was verified that the school administration is structured by democratic practices that can contribute, also, for the democratization process of the society.

Keywords

School administration; Democracy; Culture; School Council

\section{CULTURE DÉMOCRATIQUE SCOLAIRE: UNE ANALYSE DU DISCOURS DES MEMBRES DU CONSEIL SCOLAIRE}

\section{Résumé}

Cet article discute la formation d'une culture démocratique scolaire pour l'analyse du discours des membres du Conseil Scolaire de trois collèges publiques au Pernambuc. Adopte le concept de la culture proposé par Hall (1997), cela joint par l'articulation au concept du discours, en utilisant les nouvelles références théoriques de l'analyse des données empiriques. Considère que l'administration démocratique n'est pas instituée par les lois ou 
normatizations, mais qu'il y a un caractère qui pourrait être construit dans les chemins différents, dedans chaque école. II traite le discours comme entraînement social qui peut maintenir ou transformer les rapports sociaux. L'analyse des données empiriques a révélé que les significations de la construction des entraînements discursives à l'administration de chaque école est constituant de sa culture. II a été vérifié que l'administration scolaire est structurée dés le début d'entraînements démocratiques qu'ils peuvent contribuer, aussi, dans le processus de démocratisation de la société.

Mots-clé

Gestion scolaire; Démocratie; Culture; Conseil scolaire

Recebido em Abril/2009 Aceite para publicação em Julho/2010 